\title{
Use of a Reverse Bohlman Technique for Low-Grade Spondylolisthesis
}

\author{
MARTIN H. PHAM, MD, IAN A. BUCHANAN, MD, COURTNEY S. LEWIS, BS, VANCE FREDRICKSON, \\ MD, ALEXANDRA KAMMEN, BA, JOSHUA BAKHSHESHIAN, MD, FRANK L. ACOSTA JR, MD \\ Department of Neurological Surgery, Keck School of Medicine, University of Southern California, Los Angeles, California
}

\begin{abstract}
Background: Treatment of spondylolisthesis can be difficult with regard to patients with high sacral slopes that may prohibit placement of interbody grafts for fusions across that segment. Here, we describe placement of a reverse Bohlman technique from an anterior approach to obtain fusion across a low-grade spondylolisthesis with a high sacral slope to obtain anterior fusion.

Methods: A chart review was conducted on this single patient regarding his clinical course and outcome.

Results: A 54-year-old male presented with low-back pain associated with bilateral leg pain dating back several years. Plain films demonstrated a Grade II isthmic spondylolisthesis at L5-S1 with spinopelvic measurements of $73^{\circ}$ sacral slope, $82^{\circ}$ lumbar lordosis, $12^{\circ}$ pelvic tilt, and $94^{\circ}$ pelvic incidence. Magnetic resonance imaging showed bilateral L5 pars defects with diffuse degenerative disease from L4 through S1 and significant ligamentous and facet hypertrophy. He underwent an L4-5 anterior lumbar interbody fusion and an L5-S1 reverse Bohlman placement of a transvertebral transsacral titanium mesh cage. This was supplemented with a posterior decompression and instrumentation from L4ilium. He had resolution of his radiculopathy and has maintained a good clinical outcome at 3 years follow up.

Conclusions: We present here a patient with low-grade spondylolisthesis and a steep sacral slope who underwent a successful reverse Bohlman approach with long-term follow up. This report highlights the potential utility of this method as a viable alternative for patients with low-grade spondylolisthesis.

Level of Evidence: IV.

Clinical Relevance: Technical description of surgical technique.
\end{abstract}

Lumbar Spine

Keywords: spondylolisthesis, lumbar fusion, transsacral cage placement, Bohlman technique

\section{INTRODUCTION}

Although lumbar spondylolisthesis requiring operative intervention is common, there is a lack of consensus regarding management. There are several methods for achieving arthrodesis which include posterior, posterolateral, anterior interbody, and posterior interbody approaches with or without instrumentation. ${ }^{1}$ While interbody techniques are central to restoration of anterior column support, they may not be technically feasible in spondylolisthesis due to the unfavorable orientation of the vertebrae, which may preclude access to the disc space. This interbody inaccessibility, coupled with the risk of L5 nerve root injury during slip reduction maneuvers, has given rise to novel techniques for in situ fusion. ${ }^{2-4}$

In 1938, Speed et al. described their attempt at in situ fusion for high-grade spondylolisthesis at L5-S1 using a transabdominal retroperitoneal corridor for placement of a tibial strut autograft. ${ }^{5}$ This was later adapted by Bohlman and Cook in 1982 for treatment of spondyloptosis, whereby a posterior approach was taken for decompression, posterolateral fusion, and placement of an autologous fibular strut graft across the S1 vertebral body, L5-S1 disc space, and into the anteriorly positioned L5 body. ${ }^{6}$ The appeal of the Bohlman technique, which predates pedicle screw instrumentation, is that all 3 columns of the spine could be fixated through a singular incision without incurring the risk of neurologic injury from spondylolisthesis reduction or the morbidity associated with anterior lumbar exposure. Studies have shown similar fusion outcomes between the transvertebral fixation technique and more conventional methods of arthrodesis such as transforaminal interbody fusion. ${ }^{7}$ Despite its relative successes, several pitfalls have also been noted including autograft site morbidity, graft 


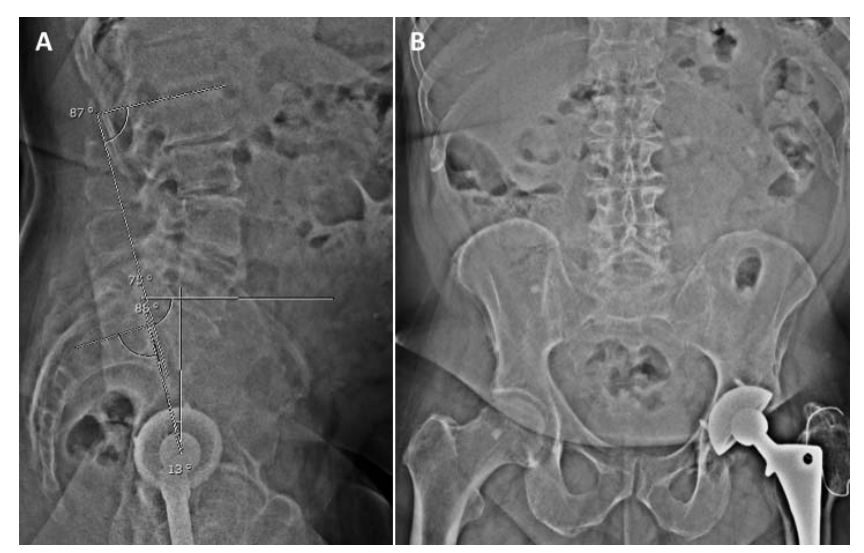

Figure 1. Preoperative anteroposterior and lateral standing radiographs obtained in a 54-year-old man with low-grade spondylolisthesis. Spinopelvic parameters were as follows: $73^{\circ}$ sacral slope, $82^{\circ}$ lumbar lordosis, $12^{\circ}$ pelvic tilt, and $94^{\circ}$ pelvic incidence.

fracture or resorption, continued slippage, pseudarthrosis, and recurrent instability. ${ }^{8-10}$

Because of the limitations of the original Bohlman method, several modifications have been made over the years both in terms of surgical approach and the adjunctive hardware placed to facilitate fusion. Examples include exchange of an osseous graft for a titanium mesh cage, the AxiaLif bolt system, and augmentation with pedicle or transsacral screw instrumentation. ${ }^{11-16}$ The reverse Bohlman method has previously been used to address high-grade spondylolisthesis. ${ }^{17}$ In the following paper, we describe the use of a modified or "reverse" Bohlman technique for placement of a transsacral cage from an anterior approach. To the authors' knowledge, this is the first such report on the use of the reverse Bohlman technique in the management of low-grade spondylolisthesis.

\section{CASE REPORT}

\section{Presentation and Examination}

A 54-year-old man presented with severe lowback pain associated with bilateral leg pain dating back several years. He reported numbness, paresthesias, and lower extremity weakness at baseline, which had all acutely worsened in the context of a recent ground-level fall. His Oswestry Disability Index (ODI) was 38. He had a normal neurologic exam. Plain radiography revealed Grade II isthmic spondylolisthesis at L5-S1 with the following spinopelvic parameters: $73^{\circ}$ sacral slope, $82^{\circ}$ lumbar lordosis, $12^{\circ}$ pelvic tilt, and $94^{\circ}$ pelvic incidence (Figure 1). Magnetic resonance imaging of the lumbar spine demonstrated bilateral L5 pars defects
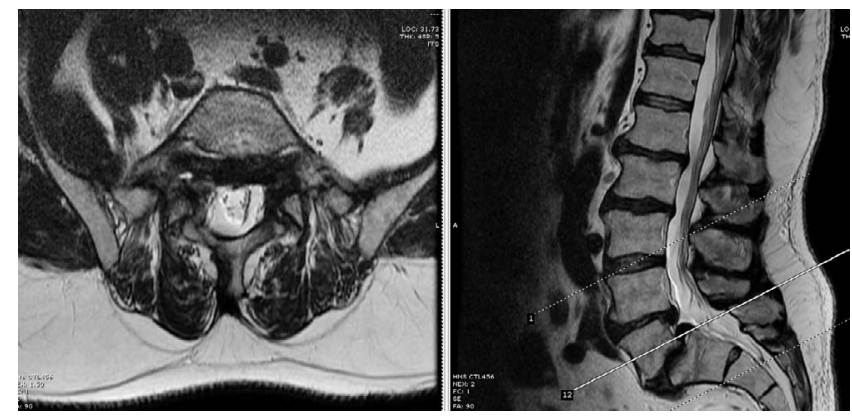

Figure 2. Axial and sagittal magnetic resonance imaging showing the L5-S1 Grade 2 spondylolisthesis with associated bilateral foraminal stenosis.

with diffuse degenerative disease from L4 through S1 (Figure 2). Additionally, significant ligamentous and facet hypertrophy resulted in moderate canal and neuroforaminal stenosis at the L5 and S1 levels. The patient had previously been managed conservatively with analgesics, physical therapy, and steroid injections. However, after failure of nonoperative management, the patient elected to undergo surgical intervention.

\section{Reverse Bohlman Technique}

An anterior approach was taken to facilitate the reverse Bohlman technique (Figure 3). A left-sided paramedian open retroperitoneal approach was performed in conjunction with vascular surgery to expose the anterior lumbar spine. A standard anterior lumbar interbody fusion was first performed at the L4-5 level. However, as the patient's sacral alignment precluded access to the L5-S1 disc space, a transvertebral transsacral titanium cage was placed through the L5 vertebral body across the L5$\mathrm{S} 1$ disc space and into the $\mathrm{S} 1$ vertebral body (Figure 4). Under fluoroscopic guidance, an awl was used to create a guide tract, followed by sequential dilation using a series of ACL drills and reamers. A $10 \times 50$ $\mathrm{mm}$ titanium mesh cage filled with allograft was ultimately placed. This anterior approach was thereafter supplemented with posterior decompression as well as pedicle screw instrumentation from L4 through S1 bilaterally with right-sided iliac screw placement.

\section{Postoperative Course}

The patient had an uncomplicated postoperative course. Postoperative x-ray and computed tomography scans showed his cage to be in good position (Figures 5 and 6). He reported considerable reduction in his back pain immediately following 


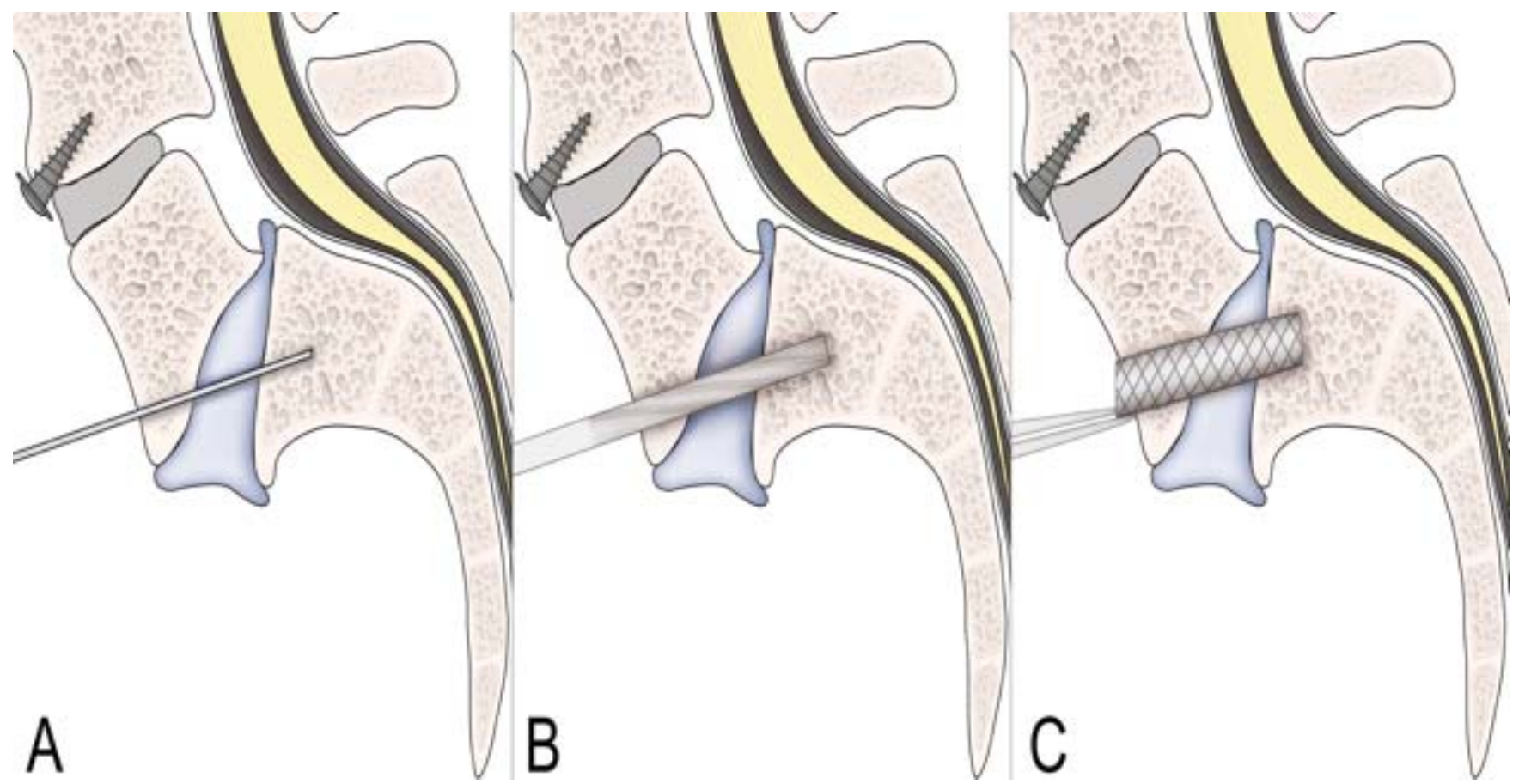

Figure 3. Schematic of reverse Bohlman approach for transvertebral transsacral cage placement in treatment of low-grade spondylolisthesis. (a) Creation of a tract across the L5 and S1 vertebral bodies. (b) Sequential dilation of tract using a series of drills and reamers. (c) Transvertebral transsacral cage placement.

the procedure along with near resolution of his lower extremity sensory disturbances. He was discharged home 7 days after his operation. At 3 years follow up, his leg pain is still resolved, and he reports an improved ODI of 28 . His x-rays show no
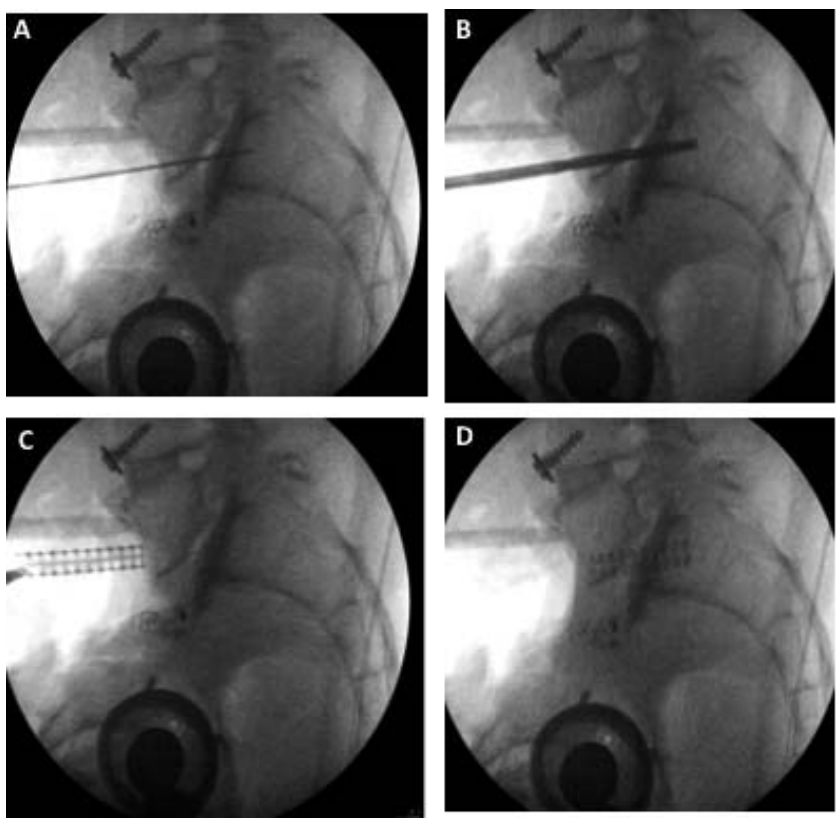

Figure 4. Intraoperative lateral radiographs demonstrating transvertebral transacral cage placement. (a) Creation of guide tract across L5 and S1 vertebral bodies, (b) dilation of tract using a series of drills and reamers, (c) initial cage placement, and (d) cage in final position. evidence of implant lucency or failure, and he remains in good sagittal alignment (Figure 7).

\section{DISCUSSION}

Surgical management of spondylolisthesis varies considerably and is influenced, in part, by surgeon preference, patient age, and biology. The lack of consensus regarding treatment stems from a lack of Level I or Level II studies to date addressing the optimal method for dealing with this condition. Some investigations have suggested that a combined anterior and posterior approach rather than either alone results in lower pseudarthrosis rates and better long-term outcomes. ${ }^{18-22}$

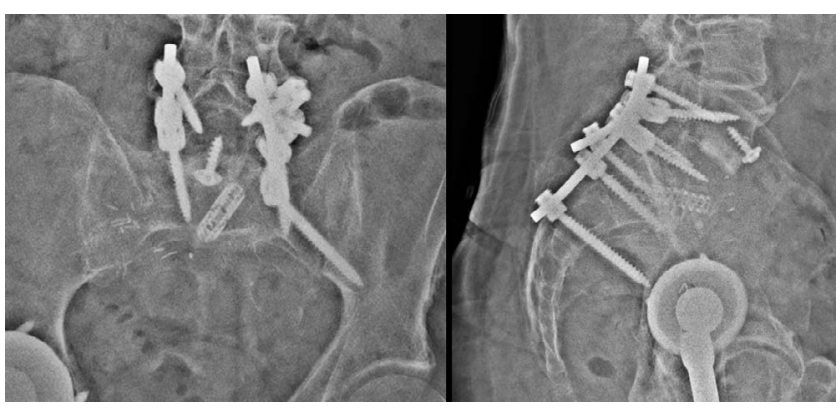

Figure 5. Postoperative standing anterior-posterior and lateral $\mathrm{x}$-ray showing the L4-ilium construct with an L5-S1 reverse Bohlman placement of the transvertebral transsacral titanium mesh cage. 


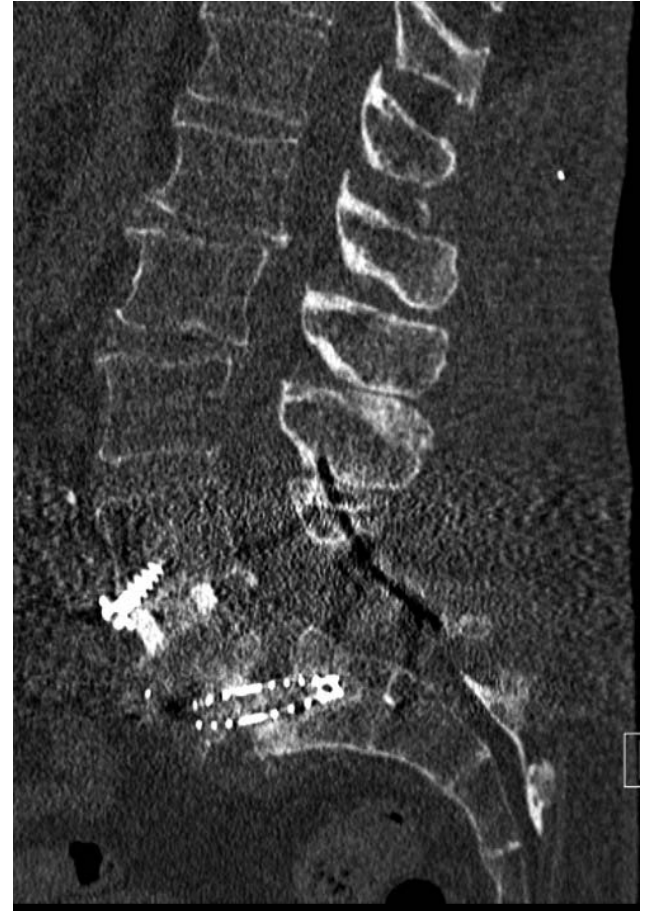

Figure 6. Postoperative computed tomography showing placement of the L5S1 transvertebral transsacral titanium mesh cage.

The Bohlman technique was originally developed in 1982 due to the high rates of fusion failure of posterior and posterolateral fusions alone, along with the higher morbidity associated with the transabdominal approach in combine operations. ${ }^{6}$ In this approach, a single-stage decompression with posterolateral and interbody fusion was used with 2 posterior transsacral autograft fibular strut grafts. Through that single posterior incision, L3 to S2 was exposed, the L5 and S1 nerve roots were decompressed with wide foraminotomies, the sacral prominence was osteotomed, and both a wire and subsequent cannulated drill bit was carefully guided into the S1 body and slipped L5 body anteriorly under fluoroscopic guidance. The fibular strut grafts were inserted and countersunk into these prepared tracts. There was no reduction of the originally described lumbosacral spondyloptosis, and since then, the technique has been shown to have very satisfactory clinical outcomes in patients with highgrade L5-S1 spondylolisthesis.

The reverse Bohlman method is generally indicated when conventional interbody approaches are not technically feasible at the lumbosacral disc space and intervention is also required at an adjacent segment. It offers several advantages: (1) elimination of durotomy risk and nerve root injury through

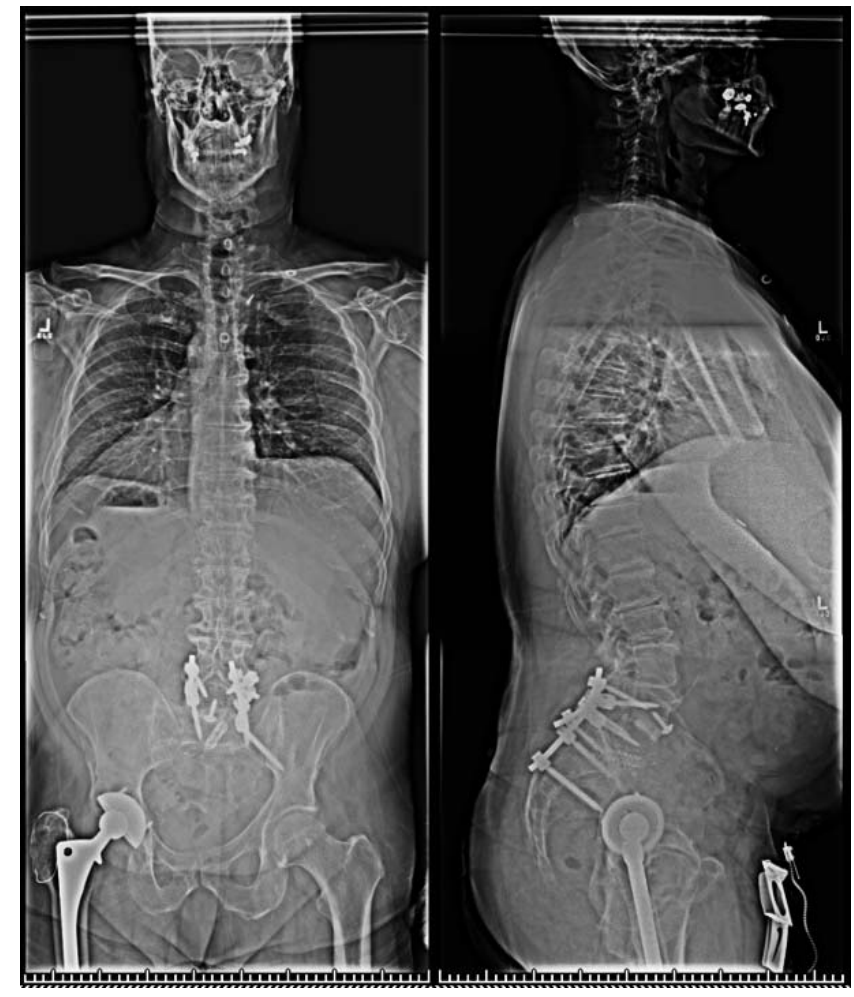

Figure 7. Three-year follow-up anterior-posterior and lateral standing films showing maintenance of his overall global alignment without any evidence of instrumentation failure.

retraction, (2) removes the need for disc preparation, which eliminates pseudoarthrosis from incomplete disc removal, and (3) less risk of neurologic injury and pseudoarthrosis secondary to implant migration. Through exposure of the anterior lumbar spine, we were able to successfully perform a standard L4-5 anterior lumbar interbody fusion followed by L5-S1 transvertebral transsacral fusion.

A central question in the management of spondylolisthesis is whether or not slip reduction adds to the efficacy of fusion or clinical outcomes. Although it seems intuitive from a biomechanical standpoint, early attempts for high-grade reduction were met with prolonged operative times, high blood losses, and an unacceptably high risk of L5 nerve root injury. Because our patient presented only with a low-grade spondylolisthesis but with a high sacral slope, we did not see a significant benefit in interbody placement and instead focused our attention on achieving a successful fusion at that segment to provide him with a favorable outcome. This was borne out on his 3-year follow up, which shows maintenance of an improved ODI and x-rays which show maintenance of good sagittal alignment without evidence of instrumentation failure. 
The Bohlman method was devised in an era before the advent of pedicle screw fixation and was born from a desire to achieve stable in situ fusion. It is also particularly useful in scenarios where the steep angle of the lumbosacral disc space precludes access for discectomy and interbody grafting, as was the case in our report. The attractiveness of the original Bohlman technique stems from the fact that all 3 columns of the spine can be fixated through a single posterior incision. Despite complications from early results with this technique, it has enjoyed relative successes, with some groups even purporting arthrodesis rates comparable to contemporary methods of interbody fusion. ${ }^{7}$ In this report, we modified a surgical technique that has previously been well described in the management of highgrade spondylolisthesis for treating a low-grade variant of the condition. While the original Bohlman method has previously been used to address spondylolisthesis of all grades, ${ }^{15-17,23}$ this is the first such report documenting a reverse Bohlman approach for low-grade spondylolisthesis.

Three years after surgery, our patient continues to maintain good sagittal alignment with complete resolution of his clinical leg symptoms and no signs or symptoms of instrumentation failure. Although fusion can only be truly assessed radiographically with advanced imaging such as a computed tomography, the stability of his implants and his clinical improvement are highly suggestive that he has gone on to a successful fusion.

\section{CONCLUSIONS}

We present here a patient with low-grade spondylolisthesis and a steep sacral slope who underwent a successful reverse Bohlman approach with long-term follow up, a treatment paradigm previously unreported in the literature. It is our hope that this report highlights the potential utility of this method as a viable alternative for patients with low-grade spondylolisthesis.

\section{REFERENCES}

1. Molinari RW, Bridwell KH, Lenke LG, Ungacta FF, Riew KD. Complications in the surgical treatment of pediatric high-grade, isthmic dysplastic spondylolisthesis. A comparison of three surgical approaches. Spine (Phila $\mathrm{Pa}$ 1976). 1999;24(16):1701-1711.

2. Bradford DS, Gotfried Y. Staged salvage reconstruction of grade-IV and V spondylolisthesis. J Bone Joint Surg Am. 1987;69(2):191-202.
3. Bradford DS, Boachie-Adjei O. Treatment of severe spondylolisthesis by anterior and posterior reduction and stabilization. A long-term follow-up study. J Bone Joint Surg Am. 1990;72(7):1060-1066.

4. Petraco DM, Spivak JM, Cappadona JG, Kummer FJ, Neuwirth MG. An anatomic evaluation of L5 nerve stretch in spondylolisthesis reduction. Spine (Phila Pa 1976). 1996;21(10):1133-1138; discussion 1139.

5. Speed K. Spondylolisthesis: treatment by anterior bone graft. Arch Surg. 1938;37:175-189.

6. Bohlman HH, Cook SS. One-stage decompression and posterolateral and interbody fusion for lumbosacral spondyloptosis through a posterior approach. Report of two cases. $J$ Bone Joint Surg Am. 1982;64(3):415-418.

7. Rodriguez-Olaverri JC, Zimick NC, Merola A, et al. Comparing the clinical and radiological outcomes of pedicular transvertebral screw fixation of the lumbosacral spine in spondylolisthesis versus unilateral transforaminal lumbar interbody fusion (TLIF) with posterior fixation using anterior cages. Spine (Phila Pa 1976). 2008;33(18):1977-1981.

8. Roca J, Ubierna MT, Caceres E, Iborra M. One-stage decompression and posterolateral and interbody fusion for severe spondylolisthesis. An analysis of 14 patients. Spine (Phila Pa 1976). 1999;24(7):709-714.

9. Smith JA, Deviren V, Berven S, Kleinstueck F, Bradford DS. Clinical outcome of trans-sacral interbody fusion after partial reduction for high-grade L5-S1 spondylolisthesis. Spine (Phila Pa 1976). 2001;26(20):2227-2234.

10. Hanson DS, Bridwell KH, Rhee JM, Lenke LG. Dowel fibular strut grafts for high-grade dysplastic isthmic spondylolisthesis. Spine (Phila Pa 1976). 2002;27(18):19821988.

11. Bartolozzi P, Sandri A, Cassini M, Ricci M. One-stage posterior decompression-stabilization and trans-sacral interbody fusion after partial reduction for severe L5-S1 spondylolisthesis. Spine (Phila Pa 1976). 2003;28(11):11351141.

12. Blumenthal SL, Ohnmeiss DD, Nass. Intervertebral cages for degenerative spinal diseases. Spine J. 2003;3(4):301309.

13. Slosar PJ, Reynolds JB, Koestler M. The axial cage. A pilot study for interbody fusion in higher-grade spondylolisthesis. Spine J. 2001;1(2):115-120.

14. Bozkus H, Dickman CA. Transvertebral interbody cage and pedicle screw fixation for high-grade spondylolisthesis. Case report. J Neurosurg. 2004;100(1 Suppl Spine):6265 .

15. Hart RA, Domes CM, Goodwin B, et al. High-grade spondylolisthesis treated using a modified Bohlman technique: results among multiple surgeons. J Neurosurg Spine. 2014;20(5):523-530.

16. Hire JM, Jacobs JM, Bundy JV, DeVine JG. A modified Bohlman technique using a novel implant for treatment of high-grade spondylolisthesis. J Neurosurg Spine. 2015;22(1):80-83.

17. Macagno AE, Hasan S, Jalai CM, et al. "Reverse Bohlman" technique for the treatment of high grade spondylolisthesis in an adult population. J Orthop. 2016;13(1):1-9. 
18. Smith MD, Bohlman HH. Spondylolisthesis treated by a single-stage operation combining decompression with in situ posterolateral and anterior fusion. An analysis of eleven patients who had long-term follow-up. J Bone Joint Surg Am. 1990;72(3):415-421.

19. Kwon BK, Hilibrand AS, Malloy K, et al. A critical analysis of the literature regarding surgical approach and outcome for adult low-grade isthmic spondylolisthesis. $J$ Spinal Disord Tech. 2005;18 Suppl:S30-S40.

20. Helenius I, Lamberg T, Osterman K, et al. Posterolateral, anterior, or circumferential fusion in situ for highgrade spondylolisthesis in young patients: a long-term evaluation using the Scoliosis Research Society questionnaire. Spine (Phila Pa 1976). 2006;31(2):190-196.

21. Molinari RW, Bridwell KH, Lenke LG, Baldus C. Anterior column support in surgery for high-grade, isthmic spondylolisthesis. Clin Orthop Relat Res. 2002;(394):109-120.

22. Muschik M, Zippel H, Perka C. Surgical management of severe spondylolisthesis in children and adolescents. Anterior fusion in situ versus anterior spondylodesis with posterior transpedicular instrumentation and reduction. Spine (Phila Pa 1976). 1997;22(17):2036-2042; discussion 2043.
23. Passias PG, Kozanek M, Wood KB. Surgical treatment of low-grade isthmic spondylolisthesis with transsacral fibular strut grafts. Neurosurgery. 2012;70(3):758-763.

Disclosures and DOI: The authors have no commercial relationships or financial interests to disclose.

Corresponding Author: Martin H. Pham, MD, Department of Neurological Surgery, Keck School of Medicine, University of Southern California, 1520 San Pablo Street, Suite 3800, Los Angeles, CA 90033. Email: martinpham@gmail. com.

Published 31 October 2019

This manuscript is generously published free of charge by ISASS, the International Society for the Advancement of Spine Surgery. Copyright (C) 2019 ISASS. To see more or order reprints or permissions, see http://ijssurgery.com. 